This item was submitted to Loughborough's Research Repository by the author.

Items in Figshare are protected by copyright, with all rights reserved, unless otherwise indicated.

\title{
Interweaving in hybrid methodologies
}

PLEASE CITE THE PUBLISHED VERSION

http://dx.doi.org/10.1080/14702029.2016.1141559

\section{PUBLISHER}

(c) Taylor \& Francis

\section{VERSION}

AM (Accepted Manuscript)

\section{PUBLISHER STATEMENT}

This work is made available according to the conditions of the Creative Commons Attribution-NonCommercialNoDerivatives 4.0 International (CC BY-NC-ND 4.0) licence. Full details of this licence are available at: https://creativecommons.org/licenses/by-nc-nd/4.0/

\section{LICENCE}

CC BY-NC-ND 4.0

\section{REPOSITORY RECORD}

Harty, Deborah, and Phil Sawdon. 2019. "Interweaving in Hybrid Methodologies". figshare. https://hdl.handle.net/2134/18257. 


\section{Interweaving in Hybrid Methodologies}

\section{Dr Deborah Harty}

Fine Art, Loughborough University, Loughborough, UK

Fine Art, Nottingham Trent University, Nottingham, UK

Epinal Way, Loughborough, LE11 3TU

\section{d.j.harty@1boro.ac.uk}

Deborah Harty is a practitioner-researcher whose research interests centre around the use of drawing practice and theory to research aspects of phenomenology, perception and experience. Her current practice-led research is investigating the premise that drawing is phenomenology. She holds a 0.5 post at Loughborough University and a 0.5 at Nottingham Trent University. Deborah is a director TRACEY drawing and visualisation research.

Deborah is also one half of humhyphenhum - a creative research collaboration with Phil Sawdon. The hums are primarily concerned with processes of drawing, including moving image, within the context of contemporary fine art; employing drawing as a means to generate understanding and further knowledge in response to a given theme.

\section{Phil Sawdon}

Honorary Fellow, Fine Art, Loughborough University, Loughborough, UK

Epinal Way, Loughborough, LE11 3TU

p.sawdon2@lboro.ac.uk

Phil Sawdon is an Honorary Fellow of the School where he spent over 20 years as a Senior Lecturer. He was a director of TRACEY drawing and visualisation research until 2015. With Marsha Meskimmon he is the co-editor of the Literature/Creative Text section of the on-line arts magazine Stimulus $\rightarrow$ Respond and, with Russell Marshall and Marsha Meskimmon, a general editor of the academic drawing series Drawing In (I.B. Tauris).. He publishes widely and in many varied formats including edited books on contemporary drawing with I.B. Tauris and Intellect. The titles include Drawing: The Purpose (Intellect, 2008), Drawing Now: Between the Lines of Contemporary Art (I.B. Tauris, 2007) and Hyperdrawing (I.B. 
Tauris, 2012), Drawing Ambiguity: Beside the Lines of Contemporary Art (I.B. Tauris with Russell Marshall, 2015) and Drawing Difference: Connections Between Gender and Drawing since the 1960s (I.B. Tauris with Marsha Meskimmon, 2015). 


\section{Interweaving in Hybrid Methodologies}

The paper will consider instances of the interweaving of theory and practice within drawing research, in order to suggest potential approaches to the development of hybrid methodologies in fine art practice-led research. The paper is written from the position of two current supervisors and creative research collaborators: Deborah Harty and Phil Sawdon (aka humhyphenhum from 2007), who historically were supervisee/supervisor.

The paper will make reference to Harty's experience as a $\mathrm{PhD}$ researcher undertaking practice-led research within a fine art context (completed 2010) and supervised by Sawdon. A discussion of Harty's hybrid methodology: action theoria, will provide an instance of the interweaving of theory and practice. Action theoria incorporates the cyclical and iterative process of action research intention; action; review - with a process of theoria - the dialogue of both practice and theory's relationship to a given subject matter.

Following this, the paper will discuss the interweaving of action theoria into humhyphenhum's collaborative research methodology: meaningful play. This interwoven methodology evolved during collaborative practice-led research projects from 2005 to the present. The paper will make reference to several of humhyphenhum's projects as a means to identify the interweaving of theory and practice within collaborative research.

As current supervisors (2015), the paper will conclude with a discussion of how reflection on these experiences has informed our position as supervisors. We will consider, for example, how this has impacted on our ability, as individual supervisors, to offer insights into the interweaving of theory and practice, without defaulting to the position of compelling our supervisees to adopt our methodology.

Keywords: practice methodology, hybrid methodology, collaboration, drawing research, meaningful play

\section{Introduction}

The paper will consider instances of the interweaving of theory and practice within drawing research, in order to suggest potential approaches to the development of hybrid 
methodologies in fine art practice-led research. The paper is written from the position of two current supervisors and creative research collaborators: Deborah Harty and Phil Sawdon (Harty and Sawdon).

Harty and Sawdon commenced as supervisee and supervisor at Loughborough University in 2005, when Harty began a practice-led PhD in drawing: drawing//experience: a process of translation. The research considered: how it is possible, through drawing, to identify and translate the elements of a specific experience into drawings? Sawdon's research theme centred around ambiguity in contemporary fine art drawing and is ongoing.

At that time, 2005 - 2009, there was a plethora of research about the relationship between theory and practice within the methodological framework both at Loughborough University and in the wider academic field of practice-led or based $\mathrm{PhD}$ research in Art and Design. For example: Barrett \& Bolt (2010), Biggs (2007, 2008), Douglas (2001), Durling (2000), Gray \& Mallins (2004), Holdridge (2006), Macleod (2002, 2006), Scrivener (2000) and Sullivan (2005, 2006). As such, this relationship formed a large part of the discussions during supervision meetings. Connected to this and regularly considered in the supervision, was the role of creative practice as a means to research rather than develop the practice per se. Therefore, a significant amount of time was spent considering the development of the methodology through discussion and 'literature' review of practice-led methodologies, interwoven with a 'literature' review around the research subject matter (drawing//experience) and context (contemporary fine art drawing). A couple of months after Harty commenced the PhD (2005), Harty 
and Sawdon began a creative collaboration, since 2007 known as humhyphenhum ${ }^{l}$, which continues to the present day. Projects undertaken include: journal exposition, moving image screenings, exhibitions and book feature. The paper will make reference to Harty's hybrid methodology: action theoria, to facilitate a discussion about the interweaving of theory and practice. Action theoria incorporates the cyclical and iterative process of action research - intention; action; review - with a process of theoria - the dialogue of both practice and theory's relationship to a given subject matter. Following this, the paper will discuss the interweaving of action theoria into humhyphenhum's collaborative research methodology: meaningful play. This interwoven methodology evolved during collaborative practice-led research projects from 2005 to the present.

The paper will make reference to several of humhyphenhum's projects as a means to identify the interweaving of theory and practice within collaborative research. As current supervisors, the paper will conclude with a discussion of how reflection on these experiences has informed our position as supervisors. We will consider, for example, how, in hindsight, this has impacted on our ability, as individual supervisors, to offer insights into the interweaving of theory and practice, without defaulting to the position of compelling our supervisees to adopt our methodology.

\section{Action Theoria}

At the beginning of Harty's PhD both Harty and Sawdon considered that it was critical that the methodology could accommodate and reconcile the relationship between the research through drawing and research through theory. It was noted at the outset that the

\footnotetext{
${ }^{1} 1$. The name was adopted following observations of various features of the hums' conversations. It is an onomatopoeic use of words. i.e. hum - hum
} 
research through theory and drawing where interdependent and necessary to pursue the research. However, the understanding of why this was the case was not initially clear. Alongside this, certain qualities were identified that were deemed pertinent to the methodology for this research project:

- Qualitative rather than quantitative

- First person research, i.e. research conducted through lived experience (Varela \& Shear, 1999)

- Interpretive, generative and emergent approach, to respond to, rather than restrict the process of discovery during the research through drawing

- Iterative with an emphasis on reflection to assess differing elements of the researched against the research aims

- Transparent

- Would allow for the multifaceted position of the researcher as both the researcher and the researched

Alongside these considerations certain methodological approaches were informing the development of the methodology:

- Naturalistic Inquiry (Gray \& Mallins 2004)

- Transcognition (Sullivan 2005, 2006)

- Action Research (Dick 1993, McNiff 2002)

- Theoria (Davy, 2006)

- Reflective practice (Schon, 1983)

It is beyond the scope of this paper to go into significant detail about the individual research methodologies. However, summarised below are the qualities each methodology contributed to the development of the hybrid methodology. 
Naturalistic Inquiry provided prompts for thinking about the emergent quality of the methodology and the role of tacit knowledge in the research. However, at the core of Naturalistic Inquiry is the siting of the research in a particular setting and therefore, Naturalistic Inquiry, as a methodology, was eventually deemed inappropriate.

Transcognition (Sullivan, 2005) highlighted the significance of an iterative process, with particular reference to revisiting elements of the research [theory and/or practice] in response to any findings. As a consequence, reflection was identified as a significant element - a tool - within an iterative dialogical process in order to know what to return to or how to proceed during: i.e. reflecting-on-action and reflecting-in-action (Schon 1983). This prompted the adoption of Reflective Practice (Schon 1983) as a part of the emerging methodology. Schon (1983) discusses in his text, 'The Reflective Practitioner' the need to make explicit, implicit processes of practice ... 'transparent'. Action Research (McNiff 2002, Dick 1993) a cyclical and iterative process of: intention; action; review, where the researcher is both the researcher and the researched, offered an approach pertinent to Harty's research. The cyclical or spiral approach to research commences with a question that Dick (1993) refers to as "fuzzy". The need for flexibility to respond to the situation necessitates an undefined initial question and as a consequence an equally fuzzy answer. Action Research provided the emergent and generative approach deemed necessary for the research, whilst accommodating the differing positions the researcher needed to adopt during the research - as both the researcher and the researched. However, whilst Action Research could accommodate research through both theory and drawing, it could not reconcile the relationship between them or offer an explanation for their interdependency.

Theoria, as interpreted by Davy (2006), offered a way of approaching the relationship between theory and practice, to allow a systemising and framing of the 
elements of the research. Davy (2006) reinterprets notions of theoria, to offer new perspectives on the way we think about the relationship of practice and theory. $\mathrm{He}$ suggests we need to cease to consider theory and practice in opposition by seeing them in relationship with each other through the commonality of the subject matter. Theoria is based on the notion that a subject matter is inexhaustible and as such it can never be completely knowable through either theory or practice. However, both can share and offer complementary perspectives that would result in a greater understanding of the subject matter; the more perspectives that can be considered, the greater our understanding of the subject matter. As understanding of the research evolved, the processes of drawing developed and alternative theories were engaged with. Therefore, it was argued, that reflection was the key to the success of both action research and theoria - elements of which were adopted for the research - and as a consequence of prime importance to the methodology. Elements of action research, theoria and reflection were subsequently combined to create a hybrid methodology - action theoria. The methodology effectively interweaves the research through theory and practice; provides the flexibility to incorporate the responsiveness and transparency required for practitioner research, whilst maintaining the rigor necessary to validate the research findings.

Alongside the supervisory relationship, and prompted by a cross-institutional drawing research project, Triptych ${ }^{2}$, Harty and Sawdon worked together on collaborative creative projects. Subsequently, as previously mentioned, this was

\footnotetext{
${ }^{2}$ DUFF, L. ... et al, 2008. Triptych : reflecting on drawing practice as knowledge. TRACEY [online]. Available from: http://www.lboro.ac.uk/departments/ac/tracey/widf/trip1.h
} [Accessed: 28 July 2008] 
consolidated as humhyphenhum in 2007. In response to a further Triptych project in 2009, humhyphenhum identified their research methodology as Meaningful Play: an interweaving of Harty's action theoria and other emergent collaborative approaches, including play and dialogue. Interwoven into the process and acknowledgement of an emerging methodology was the varying position of the researchers throughout the last ten years: from supervisee/supervisor, with projects led by Sawdon, to a more level position as academic researchers.

\section{Collaboration/Meaningful Play: collaborative researchers}

As humhyphenhum, the first time we openly thought about our collaborative process/methodology, suggesting it was meaningful play, was in response to an invitation to contribute, through Pivot $^{3}$ to the 'unorthodox' section of Animation in Process (Selby, A. 2009). Animation in Process invited us to reflect on our process, in order to make it explicit to its readership. At the time we made suggestions about the nature of our process from the perspective of creative collaborators, for example:

- We play/mark-make through trial and error around a developing shared aesthetic.

- We reflect on and respond to the emerging work. The composition therefore, emerges and develops through a process of responsiveness and rigorous meaningful play.

\footnotetext{
${ }^{3}$ Pivot was Harty \& Sawdon's contribution to Triptych: a drawing research collaboration between Dublin Institute of Technology, Loughborough University \& Kingston University which explored practice and theory in order to contribute to knowledge of the act of drawing: https://dspace.lboro.ac.uk/dspace-jspui/handle/2134/3491
} 
- The work develops a logic, and coherent strategy as we think, talk and play. The logic may not be transparently evident but it is there. We talk and click and talk and click and ...

- Our process is initially empirical, developing from experience, particularly sensory experience, rather than a consistent application of logic or structure.

- We do not illustrate a theory or position; we hope to create a position as and through our process. However, a consistent, acknowledged, strategy/structure for decisions and form emerges through the process of making and responding (Harty \& Sawdon 2009 in Selby 2009).

It is worth noting at this point that our process involves us working together in a space, we don't work independently on various elements, which are them brought together. We create the work side-by-side or opposite each other. Interwoven into the above points were identifiable elements of action theoria: reflection, responsiveness etc. However, at the time, unlike Harty's doctoral thesis, we were not writing within an academic research context and therefore, the language and emphasis differed from that which we now use to discuss our methodology. We would still identify the points above as integral to our current methodology. However, through attention to and reflection on our methodology, during various subsequent projects and in addition the changing nature of our academic positions, we made a conscious decision to work within an academic research context ${ }^{4}$. Consequently, we took the decision to assemble a multimodal journal exposition The taste of tree? (2012) for the Journal of Artistic Research. The inspiration for this research project was born out of Harty's \& Sawdon's

\footnotetext{
${ }^{4}$ Harty became an academic following the completion of her doctoral studies and Sawdon's became an Honorary Fellow.
} 
concurrent individual practices. Harty was developing elements of her doctoral research to focus on the relationship between drawing and phenomenology under the umbrella 'drawing is phenomenology'. Sawdon was investigating the relationships within contemporary fine art drawing and ambiguity through text/prose, digital drawing and moving image and an emerging interest in drawing as a phenomenological process, potentially able to record the world as it appears to consciousness rather than how we perceive it to be.

The taste of tree? (2012) considered whether the senses are connected and transferable in memory sufficiently to draw the taste of tree through the association of recalled sensations, whilst revealing the research process by providing a critical commentary of the practice as research. Reflecting on that methodological approach in order to construct this paper, we acknowledge the following qualities, we would recognise as directly correlating with those identified within action theoria, inherent in meaningful play:

- Qualitative approach

- Research conducted through lived experience

- Interpretive, generative and responding to emergent discoveries during the research process

- Iterative

- Reflective

- Transparent

- Allows for the multifaceted position of the researcher/s as both the researcher and the researched 
However, in addition to the qualities listed above, meaningful play is acknowledged as a phenomenological methodology ${ }^{5}$ that also interweaves the following:

- Play

- Mutuality

- Dialogue

\section{Play}

Informed by Zimna's (2010) discussion of play as a frame within in which to make artwork, we recognise that we play as a meaningful way to generate 'stuff'. This is distinct from Huizinga (in Zimna, 2010, p.21) notions of “... play as a voluntary activity, performed with no practical or material interest, just for fun and with pleasure." This definition of play is generally related to childhood: “... joyful, non-serious, sometimes mysterious or irrational and opposed to the sphere of purposeful adult's activities" (Zimna, 2010, p.15). Our play is not a disinterested pretence nor is it an "activity pursued for its own sake." We play to experiment, to attempt to: push our understanding; avoid repeating familiar motives; be open-ended; change the process to put ourselves in an unfamiliar situation within a frame[work] in order to bring something fresh to the work. Our meaningful play is a conceptual frame and a means of

\footnotetext{
${ }^{5}$ A phenomenological approach was not identified as a quality of action theoria at the time.
} However, it is arguable in hindsight, as a consequence of a greater understanding of phenomenology, that it was evident as an approach within Harty's research. The taste of tree? (2012) was phenomenological in its approach, due to a decision to align the various research strands of Harty \& Sawdon as individuals. Phenomenological we take to mean to capture lived experience as it appears to consciousness. 
engaging with creative research processes to develop our collective understanding around a particular experience or theme. This can involve activities that may specifically relate to childhood play, for example, in The taste of tree? (2012) the camera (operated by Harty \& Sawdon) 'played' hide and seek. The decision to play came from our discussions of 'treeness', within which we both identified strong memories of playing hide and seek in and around trees in our childhood. However, whilst we operated within the 'rules of play' of hide and seek, our intention was to attempt to encapsulate the experience of playing hide and seek, with play as the framework and prompt for actions rather than actually playing the game of our childhood. Interweaving experiences whilst bringing theory into play. The process of play began with an intention to play amongst the trees with the camera. Play commenced intuitively, with the camera passing between us, in response to the developing play. This initiated periods of time of absorption and silent activity within the play. Reflection-in-play (action) continued and was informed by theory, however at several points there were brief pauses to consciously reflect-on-play (action) through the lens of theory. This in turn, informed the next action: for example, a change of media or location, until the intuitive play comes to the fore again. Zimna (2010, p. 53) states

Play, as a movement "in between", allows for the states of rational, subjective control and the states of being lost, immersed in, and completely absorbed by the events and sensations. Players/participants play their game but at the same time they are played by this game. It is a two-way process.

\section{Mutuality}

Our play depends on mutuality: mutual respect whilst collaborating during the process and mutual responsibility for the outcome. Robson \& Córdoba (2005) in 'What Research Methodology suits Collaborative Research' state that there are two layers 
within collaborative research: the first is the co-operation layer, which involves the collaborative process. The second is the outcome layer.

The co-operation layer involves creating and sustaining an environment of mutual respect, in which the diversity of views is continuously recognised. Each is equally committed to the project and respects the other's opinions. For example, if one of us has an issue with a particular aspect of the process or developing drawing(s), it is subject to any degree of change to address the concerns raised even if the other doesn't share the concern. Equally, if one of us feels very strongly about a positive aspect of the developing work, the other will agree to pursue that direction. The strongest thought and/or feeling determines the direction and/or outcome due to mutual respect for the other's judgement. This is perhaps a consequence of shared ownership of the outcome.

The outcome layer, in our collaboration, continuously informs and interweaves with the process layer. There is a level at which we predetermine the outcome, with regards to potential media and/or platforms we will work with: text, moving image, installation etc. However, due to the reflective and responsiveness of our collaborative process, the final form and content of the outcome is perpetually modified and therefore subject to change. For example, when commencing the drawing $I[w h o . . . ?] y o u \_y o u[m e] U s$ we were responding to an invitation to contribute to an exhibition: drawology 2013 at the Bonington Gallery, Nottingham. There were no restrictions on media, scale etc. I[who...?]you_you[me]Us followed on from The taste of tree?, where we paid particular attention to our methodological process. This informed our decision to document through film the collaborative processes from initial discussion to final outcome. During initial discussions of what the potential outcome may be, we decided to make the outcome replicate the process of its making. Therefore, as we were positioned either side of a table during these initial discussions, this 
instigated the notion of including a table in the final outcome, potentially using it as a projection screen. This basic premise didn't change and a table, with stools positioned in opposing sides, was part of the final outcome: an installation. The form and content of the installation were developed through the collaborative creative process.

\section{Dialogue}

As previously stated, as a result of constructing this paper we have identified dialogue as an important element of our collaborative methodology. The importance of dialogue can be traced back to transcognition (Sullivan, 2005), cited within Harty's action theoria above, where dialogue is said to happen between artist, artwork, viewer and setting in order to develop meaning and was extended when creating The taste of tree?, as a fifth entity 'Sawdon' added to the dialogue. This was further extended when the dialogue was drawn-out to a third collaborator, Lucy O’Donnell, for the project Mooquacious Wutterances, a collaged moving image drawing, where we used what we referred to as 'conversational dialogue' as the means and content of the outcome. However, it was not previously acknowledged as a fundamental, multifaceted element of our methodology. We would now suggest that several modes of interwoven dialogue form the 'dialogue' in our methodology:

So in summary, we now recognise our meaningful play methodology as incorporating the following elements:

- Qualitative approach

- Phenomenological: research conducted through lived experience

- Interpretive, generative and responding to emergent discoveries during the research process 
- Iterative

- Reflective

- Transparent

- Allows for the multifaceted position of the researcher/s as both the researcher and the researched

- Play

- Mutuality

- Dialogue

So in summary, we now recognise our Meaningful Play methodology as incorporating the following elements:

- Qualitative approach

- Phenomenological: research conducted through lived experience

- Interpretive, generative and responding to emergent discoveries during the research process

- Iterative

- Reflective

- Transparent

- Allows for the multifaceted position of the researcher/s as both the researcher and the researched 
- Play

As current supervisors, we will conclude with a discussion of how reflection on our methodology, meaningful play, has informed our position as supervisors.

\section{Supervision}

At the time of writing, we are not co-supervisors of a doctoral research project, however we are both currently supervising projects that necessitate the interweaving of theory and practice. In the collaborative creation of this paper, we have become mindful that our individual approach as supervisors incorporates comparable elements to our collaborative creative methodology; when supervising there are certain non-hierarchical elements of meaningful play that resonates with our approach:

- Iterative: we [as supervisors] question, listen, respond, question ...

- Interpretive, generative and responsive; the importance of asking questions in response to the emerging discussion.

- Dialogue: understanding [supervisee] develops through dialogue; often in attempting to address a question the light goes on.

Through these approaches we offer provocations to generate thinking in response to the individuals' research project including the interweaving of theory and practice. It may be tempting, during supervision, to advocate methodological paradigms, meaningful play for example, as a 'quick fix' to reconcile the relationship between theory and practice. However, we suggest here, that a more pertinent approach is to use the supervision to create a focused space to consider and question in order to arrive, over time, at an understanding of the relationship between theory and practice. 
Allowing the student to move from thinking of theory as a separate entity to thinking of it in terms of context, which when interwoven with practice has the potential to create an appropriate critical framework within the project's field.

\section{Postscript}

Through these approaches we offer provocations to generate thinking in response to the individuals' research project including the interweaving of theory and practice. It may be tempting, during supervision, to advocate methodological paradigms, meaningful play for example, as a 'quick fix' to reconcile the relationship between theory and practice. However, we suggest here, that a more pertinent approach is to use the supervision to create a focused space to consider and question in order to arrive, over time, at an understanding of the relationship between theory and practice. Allowing the student to move from thinking of theory as a separate entity to thinking of it in terms of context, which when interwoven with practice has the potential to create an appropriate critical framework within the project's field.

Davy, N. 2006. “Art and Theoria”, in, Macleod, K. \& Holdridge, L. ed. 2006. Thinking through Art-reflections on art as research, London: New York: Routledge. pp. 20-39. Dick, B.1993, You Want to do an action research thesis? http://www.scu.edu/schools/gcm/ar/art/arthesis.html Accessed: 4 December 2007 Gray, C. \& Malins, J. 2004. Visualising Research - A Guide to the Research Processes in Art and Design, Hants. Burlington: Ashgate Publishing Ltd.

Harty, D. \& Sawdon P. as humhyphenhum 2012. Journal for Artistic Research, 2, http://www.researchcatalogue.net/view/344/345/0/0. Accessed 7th November 2012 Harty, D. \& Sawdon P. 2009. "Unorthodox" in Selby A. 2009. Animation in Process, London: Laurence King Publishing Ltd pp.154-7

Huizinga, J. 2007. in Zimna K. "Play in the Theory and Practice of Art" PhD diss. Loughborough University 2010

McNiff, J. 2002. Action Research for Professional Development. 
http//:www.jeanmcniff.com/booklet1.html

Accessed 3 October 2008

Robson, W. \& Córdoba, J. 2005. What Research Methodology suits Collaborative Research, Hull: The University of Hull Business School.

Schon, D. A. 1983. The Reflective Practitioner - How Professionals Think in Action, London: Temple Smith.

Sullivan, G. 2005. Art Practice As Research - Inquiry in the Visual Arts, Thousand Oaks. London. New Delhi: Sage Publications.

Sullivan, G. 2006. “Artefacts as evidence within changing contexts”, Working Papers in Art and Design, Vol. 4.

http://www.herts.ac.uk/artdes1/research/papers/wpades/vol4/gsfull.html Accessed 14 June 2007

Varela, F.J. \& Shear, J. 1999. “First-person Methodologies: What, Why, How?” in Journal of Consciousness Studies, 6, No. 2-3, 1999, pp. 1-14

Zimna, K. "Play in the Theory and Practice of Art" PhD diss. Loughborough University 2010 